\title{
A Commentary on "A Novel Imaging Finding in Williams Syndrome: The Coral Sign"
}

\author{
Ali M Agha', Jeremy Burt ${ }^{2 *}$ \\ 'The McGovern Medical School at UT Houston, Department of Internal Medicine, USA
}

${ }^{2}$ AdventHealth Orlando, Department of Radiology, USA

\section{Article Info}

\section{Article Notes}

Received: April 11, 2019

Accepted: May 6, 2019

*Correspondence:

Dr. Jeremy Burt, 601 E Rollins St, Mail Stop 163, Orlando,

FL 32803, USA; Telephone No: 407-303-8178; Fax No: 407-

303-2898; Email: Jeremy.Burt.MD@adventhealth.com.

( 2019 Burt J. This article is distributed under the terms of the Creative Commons Attribution 4.0 International License.
We recently published "A Novel Imaging Finding in Williams Syndrome: The Coral Sign" in Pediatric Radiology. In this publication, we described a patient with Williams-Beuren Syndrome who underwent cardiac magnetic resonance (CMR) imaging after presenting with dizziness. Initially, the patient underwent echocardiography, which showed an unusual and abnormal appearance of the interventricular septum. Subsequent CMR further clarified the findings by showing septal thickening, thickened muscular trabeculations and linear bands of myocardium crossing the ventricle. This constellation of findings produced an image which resembled "coral" found on the ocean floor. This had not been previously described in the literature, and we declared this finding "the coral sign"1.

At its surface, we describe a unique imaging finding on CMR that may help physicians identify a cardiovascular manifestation of Williams Syndrome. However, a more holistic review of this case report reveals a paradigm shift in the field of cardiovascular imaging. Previously, cardiologists viewed echocardiography as the gold standard to identify structural heart disease ${ }^{2}$. Echocardiography has advantages over other imaging modalities with its low-cost, ready accessibility, and ease of use. However, echocardiogram image quality may suffer from poor acoustic windows and poor reproducibility. These findings have been shown many times, including an interstudy reproducibility comparison with $\mathrm{CMR}^{3}$.

Among patients with Williams Syndrome, most of the cardiovascular manifestations described in the literature (supravalvular aortic stenosis, peripheral pulmonary arterial stenosis, mitral valve prolapse, and mitral valve regurgitation ${ }^{4}$ ) were identified on echocardiography. However, these echocardiographic manifestations can be found in a multitude of cardiovascular disorders, and thus lack specificity. In contrast to echocardiography, findings on CMR in cardiovascular diseases are often more reliable, sensitive and specific, and this modality is beginning to play a much greater role in the field of cardiovascular imaging ${ }^{5,6,7}$. The Congenital Heart Disease Compendium published in Circulation in 2017 noted “... CMR remains the gold standard for evaluating cardiac anatomy and function in congenital heart disease ... ${ }^{8 \prime}$ The European Society of Cardiology made a similar recommendation for adults with congenital heart disease ${ }^{9}$.

For example, let us consider the diagnosis of cardiac amyloidosis. Previously, echocardiographic findings such as left ventricular 
wall thickening and a reduced ejection fraction in a patient with AL amyloidosis may have given clues to the diagnosis ${ }^{10}$. However, these findings are non-specific and often present late (when the disease process is invariably fatal). In contrast, advances in CMR may allow for early diagnosis of cardiac amyloidosis, even among patients with normal echocardiograms. Specifically, elevations in the extracellular volume fraction (ECV) on CMR can be identified even when hypertrophy is not appreciated on echocardiography ${ }^{11,12}$. This implies that CMR may be more sensitive than echocardiography for the diagnosis of cardiac amyloidosis. Furthermore, non-contrast or native T1 times on CMR are significantly elevated in cardiac amyloidosis compared to those with left ventricular hypertrophy (LVH) due to aortic stenosis ${ }^{13}$, implying that CMR may also be more specific than echocardiography in this setting.

Likewise, we anticipate that "the coral sign" and other CMR findings in Williams-Beuren syndrome will be more sensitive and/or specific than their echocardiographic counterparts. We challenge our radiology and cardiology colleagues alike to identify unique findings on CMR that may aid in the early and more accurate diagnosis and treatment of various cardiovascular disease processes. Presently, CMR technology is not available in countries with limited resources. As the utility of CMR becomes more apparent, the number of institutions that have this technology becomes more readily available, and the cost-effectiveness continues to improve ${ }^{14}$, we expect CMR to become the preferred modality for the identification of structural heart disease.

\section{References}

1. Burt JR, Beavers K, Kendall M, et al. A Novel Imaging Finding in Williams Syndrome: The Coral Sign. Pediatr Cardiol. 2018.

2. Ciampi Q, Villari B. Role of echocardiography in diagnosis and risk stratification in heart failure with left ventricular systolic dysfunction. Cardiovasc Ultrasound. 2007; 5: 34.
3. Grothues F, Smith GC, Moon JC, et al. Comparison of interstudy reproducibility of cardiovascular magnetic resonance with twodimensional echocardiography in normal subjects and in patients with heart failure or left ventricular hypertrophy. Am J Cardiol. 2002; 90(1): 29-34.

4. Pober BR. Williams-Beuren syndrome. N Engl J Med. 2010; 362(3): 239-52.

5. Brunklaus A, Parish E, Muntoni F, et al. The value of cardiac MRI versus echocardiography in the pre-operative assessment of patients with Duchenne muscular dystrophy. Eur J Paediatr Neurol. 2015; 19(4): 395-401.

6. Jaarsma C, Schalla S, Cheriex EC, et al. Incremental value of cardiovascular magnetic resonance over echocardiography in the detection of acute and chronic myocardial infarction. J Cardiovasc Magn Reson. 2013; 15: 5.

7. Agha AM, Parwani P, Guha A, et al. Role of cardiovascular imaging for the diagnosis and prognosis of cardiac amyloidosis. Open Heart. 2018; 5(2): e000881.

8. Burchill LJ, Huang J, Tretter JT, et al. Noninvasive Imaging in Adult Congenital Heart Disease. Circ Res. 2017; 120 (6): 995-1014.

9. 9. Kilner PJ, Geva T, Kaemmerer H, et al. Recommendations for cardiovascular magnetic resonance in adults with congenital heart disease from the respective working groups of the European Society of Cardiology. Eur Heart J. 2010; 31(7): 794-805.

10. 10. Mohty D, Damy T, Cosnay P, et al., Cardiac amyloidosis: updates in diagnosis and management. Arch Cardiovasc Dis. 2013; 106(10): $528-40$.

11. Banypersad SM, Sado DM, Flett AS, et al. Quantification of myocardial extracellular volume fraction in systemic AL amyloidosis: an equilibrium contrast cardiovascular magnetic resonance study. Circ Cardiovasc Imaging. 2013; 6(1): 34-9.

12. Burt JR, Zimmerman SL, Kamel IR, et al. Myocardial T1 mapping: techniques and potential applications. Radiographics. 2014; 34(2): 377-95.

13. Karamitsos TD, Piechnik SK, Banypersad SM, et al. Noncontrast T1 mapping for the diagnosis of cardiac amyloidosis. JACC Cardiovasc Imaging. 2013; 6(4): 488-97.

14. Greulich S, Arai AE, Sechtem U, et al. Recent advances in cardiac magnetic resonance. F1000Res. 2016; 5. 